\title{
Redescubriendo la Gran Chichimeca: Revalorización regional y antropología social en la recuperación de una pluralidad étnica mexicana
}

\author{
Rediscovering The Great Chichimeca: \\ Regional Assertiveness and Social Anthropology \\ in the Rehabilitation of a Mexican Ethnic Plurality
}

\author{
Pedro Tomé \\ Grupo de Investigación "Antropología \\ Comparada de España y América" (ACEA) \\ Centro de Ciencias Humanas y Sociales. CSIC. Madrid
}

\section{RESUMEN}

Durante siglos el término "chichimeca" ha sido utilizado por los mexicanos como sinónimo de "bárbaro" o "salvaje". Sin embargo, en las últimas décadas una profundización en el conocimiento de los grupos chichimecas — a la que no ha sido ajena una re-valorización política de las regiones en México- ha propiciado una nueva reconstrucción de la memoria de la conquista española que, en parte, ofrece una visión distinta de estos grupos humanos. En un grado no previsto, la antropología social - y, en particular, el "Seminario Permanente de Estudios de la Gran Chichimeca" (SPECH), en el que diferentes disciplinas académicas dialogan sobre un mismo tema y un mismo territorio- está contribuyendo a la misma revisión, con el resultado convergente de sacar a los pueblos chichimecas del ostracismo al que la historia oficial en México los había confinado, mientras se genera, entre otros habitantes de esa parte del país, un cierto orgullo de ser del mismo lugar que ellos.

Palabras clave: Gran Chichimeca, México, Nomadismo, Antropología Social, SPECH, Historia de la antropología.

\section{SUMMARY}

For centuries Mexicans have used the term "Chichimeca" as a synonym for "Barbarian" or "Savage." However, in the past decades a deeper understanding of the Chichimeca peoples — largely affected by a political assertiveness of the regions in Mexico- has 
resulted in a fresh reconstruction of the memory of the Spanish conquest and, thereby, of the view of these peoples. To a unexpected extent, social anthropology - particularly, the "Seminario Permanente de Estudios de la Gran Chichimeca" (SPECH), promoting regular discussions and publications on the subject from different academic disciplines- has contributed to this rehabilitation as well. A convergence is thus emerging between new scholarly interest in the indigenous nations of Mexico's northern frontier - taking the Chichimeca out of the ostracism to which official history in the country had confined them - and a newly found reason for pride among the rest of the population in belonging to the same area.

Key words: Great Chichimeca, Mexico, Nomadic Existence, Social Anthropology, SPECH, History of anthropology.

\section{De "La Gran Chichimeca" a los ChichimeCAS}

La rápida caída de la Gran Tenochtitlan hizo concebir a los conquistadores un fulminante paseo militar por todo el continente recién descubierto. Sin embargo, tales deseos se vieron frustrados cuando encaminaron sus pasos y armas en dirección hacia la tierra que los mexicas denominaban "Chichimecatlalli - o 'Tierra de los Chichimecas'- y también Teotlalpan Tlacochcalco Mictlampa o 'campos espaciosos que están hacia el norte-lugar de la muerte"” (Braniff 2001a: 7). En tan vastos territorios los conquistadores desataron una cruel guerra que se prolongaría durante casi un siglo. Dirigidos por Tenamaxtli (o Tenamaztle) y Guaxicar (Weigand y García 1996), los grupos nómadas y seminómadas que recorrían los vastos territorios situados al norte del río que después se llamaría Lerma-Santiago propiciaron una tenaz resistencia, conocida con el nombre de "Guerra Chichimeca" (Powell 1977; Carrillo 2000; Carrillo 2003) (véase Mapa 1).

La narración de este conflicto bélico por los cronistas imperiales, particularmente tras lo acontecido en 1541 en la batalla del Mixtón, sirvió para identificar a estos grupos con la crueldad máxima ${ }^{1}$. Esta percepción, unida posteriormente al muy extendido prejuicio evolucionista que considera el

${ }^{1}$ Como dijera Fray Guillermo de Santa María, autor de uno de los primeros tratados sobre los chichimecas, "son por todo extremo crueles, que es la mayor señal de su brutalidad. A la persona que prenden, ora sea hombre o mujer, lo primero que hacen es hacerles de corona, quitando todo el cuero y dejando todo el casco mondo, tanto como toma una corona de un fraile, y esto estando vivos, y yo vi un español sin él, a quien ellos se le quitaron, y a la mujer del Copoz también se le quitaron y han vivido sin él muchos días, y aun creo que viven hoy. Quítanles ansí mismo los nervios para con ellos atar los pedernales en sus flechas. Sacándoles las canillas, ansí de las piernas como de los brazos, vivos, y aun a las veces las costillas, y otras cien crueldades, hasta que el mísero entre ellas despide el ánima" (Carrillo 2003: 208). 


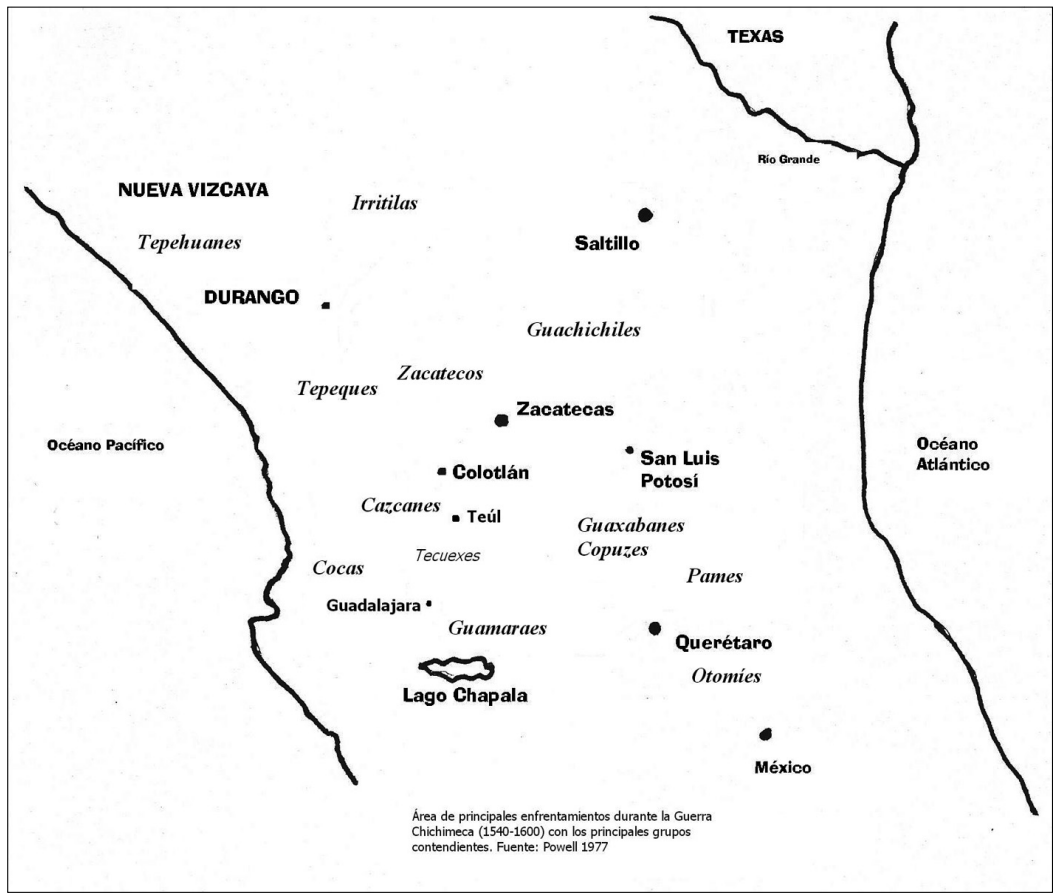

MAPA 1: Área de los principales escenarios bélicos durante la Guerra Chichimeca, según Powell (1977).

nomadismo como una etapa de desarrollo anterior a la civilización, propició una equiparación de los términos "chichimeca", "bárbaro" y "salvaje" a lo largo de la colonia que todavía perdura entre numerosos mexicanos, quienes utilizan dicho vocablo como cotidiana injuria. En este sentido, más allá de una difusa identificación del apelativo chichimeca con ciertas danzas queretanas en las que se venera la Santa Cruz, la unión de los términos "chichimeca" y "salvaje", fortalecida por el desdén con que una construcción nacional centralista miró al resto del país, ha generado en gran parte de la sociedad mexicana un nítido rechazo hacia todo aquello que pudiera ligarse a ese vago término.

De este mismo menosprecio también ha bebido históricamente tanto una parte de la intelectualidad mexicana - como lo atestiguarían las palabras, entre otros, de José Vasconcelos- como las propias ciencias sociales. De hecho, el nombre mismo de "Gran Chichimeca", con el que tanto mexicas como conquistadores conocieron a esos espacios que se extendían hasta los actuales Estados de Utah y Colorado, ha sido frecuentemente rechazado por científicos sociales de diferentes especialidades, atendiendo a una plurali- 
dad de motivos de diversa índole. Para algunos se trata simplemente del territorio que Kroeber, desde los Estados Unidos, había llamado "El Suroeste" y que, visto desde México, puede definirse como "El Noroccidente" sin entrar en mayor consideración. Más son los que, asumiendo a propio intento o inintencionadamente la teoría de áreas de Kirchoff, lo identifican con "Aridoamérica" 2 . Por último, no puede desdeñarse en la explicación de este repudio el aludido prejuicio evolucionista que identifica a los nómadas con bárbaros harapientos de los que, lógicamente, nadie quiere descender.

Sin embargo, incluso concediendo que hubiera una identificación entre el área definida por Kirchoff y la Gran Chichimeca, las mencionadas definiciones geográficas desconsideran, de un lado, gran parte de los elementos culturales que contribuyen de manera decisiva a la configuración de la región y, de otro, las poblaciones mismas que en ella habitaron y donde hoy viven. A mayores, definir este espacio por su ubicación geográfica en relación con Berkeley o con la Ciudad de México supone una caracterización muy del gusto de quienes rechazan la posibilidad de desarrollos culturales endógenos que, en el caso mexicano, se concreta en la creencia de que cualquier transformación positiva, para sustanciarse, ha de partir del centro. Además, esta caracterización exógena se ha nutrido inicuamente tanto del recuerdo de una imaginaria barbarie como, sobre todo, de una imprecisa equivalencia que se establece entre ecosistemas particulares, cual son los desiertos, y el vacío absoluto en el que no es posible la vida y mucho menos la cultura (Mapa 2).

El desenvolvimiento histórico de la antropología tampoco ha sido ajeno a esta perniciosa mirada. Las primeras crónicas de la Conquista muestran el asombro que en los conquistadores suscitaron las grandes urbes, los magníficos templos y descomunales pirámides, así como una agricultura desarrollada y poderosos ejércitos con que se hallaron en el centro y sur de lo que hoy es México. Frente a tanto esplendor, los norteños chichimecas fueron presentados como su antítesis: andrajosos seminómadas que, a pesar de malvivir en una indigencia tan extrema que les obligaba a alimentarse de sus propios excrementos, se convertían en un auténtico peligro para el orden social tanto por su crueldad como, sobre todo, por su incapacidad para propiciar algún tipo de organización social. O dicho de otro modo: la imposibilidad de una asimilación —forzosa o voluntaria- hizo que los

${ }^{2}$ En su pretensión de aplicar los criterios emanados de las teorías difusionistas Paul Kirchoff (1943) estableció una hipotética división de "áreas culturales" del territorio americano. De acuerdo con esta segmentación del territorio, postuló la existencia de un área, "Aridoamérica", que se situaría al norte de la nuclear Mesoamérica, siendo el límite hipotético de separación entre ambas una imaginaria línea coincidente con los ríos SinaloaSantiago-Lerma y Pánuco. 


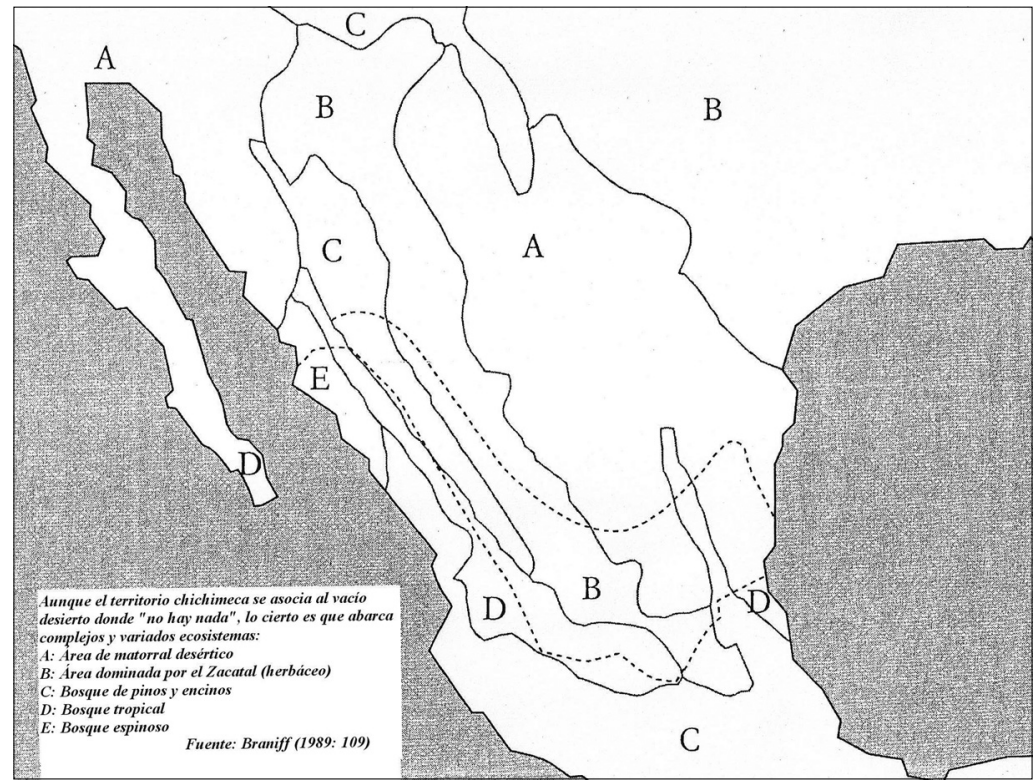

MAPA 2: Aunque frecuentemente se asocia el territorio chichimeca al vacío donde nada hay, lo cierto es que abarca complejos y variados ecosistemas: A. área de matorral desértico; B. área de zacatal (herbáceos); C. Bosque de pino-encino;

D. Bosque tropical; E. Bosque Espinoso. Fuente: Braniff (1989: 109).

chichimecas pudieran ser utilizados - como si fueran "armas de destrucción masiva" en manos de un potencial enemigo- para justificar el arribo de un desmesurado contingente militar.

El inevitable eurocentrismo de los cronistas, que permeó toda la época colonial, vino a reforzarse posteriormente con las teorías propias del decimonónico evolucionismo cultural. Así, las definiciones más persistentes que se han realizado de los chichimecas se acomodarían casi milimétricamente a las características conformadoras de los estadios superior de salvajismo o inferior de barbarie, según la conocida taxonomía del desarrollo cultural que Lewis H. Morgan publicara en 1877. De hecho, según esta misma clasificación, las monumentales culturas del centro y sur de México - supuestamente mucho más avanzadas - eran consideradas prototipo de un estadio medio de barbarie ${ }^{3}$. Con ello se fortalecían las condiciones de posi-

3 "This places in the Middle Status [of barbarism], for example, the Village Indians of New Mexico, Mexico, Central America and Peru, and such tribes in the Eastern hemisphere as possessed domestic animals, but were without a knowledge of iron" (Morgan 1985: 11). Estas ideas se vieron reforzadas aún más por la presentación de la "democracia militar" mexicana en la obra de Bandelier (1880). 
bilidad para que en el periodo post-revolucionario del siglo xx se robusteciera lo que Octavio Paz (1967), más allá de sus posicionamientos contra una forma de hacer etnografía, denominara el "punto de vista nahua", esto es, la identificación de lo prehispánico con lo azteca (Foto 1). Según Paz, este punto de vista nahua hallaría plena concreción en la construcción del Museo Nacional de Antropología, en el que se ofrece una "imagen falsa" (Paz 1970: 153) del pasado precolombino debido a que "no obedece tanto a las exigencias de la ciencia como a la estética del paradigma" (ibid: 151). Justamente por tal motivo resulta particularmente relevante observar cómo aparecen presentados los chichimecas dentro de las salas que en dicho museo se dedican a las denominadas "Culturas del norte".

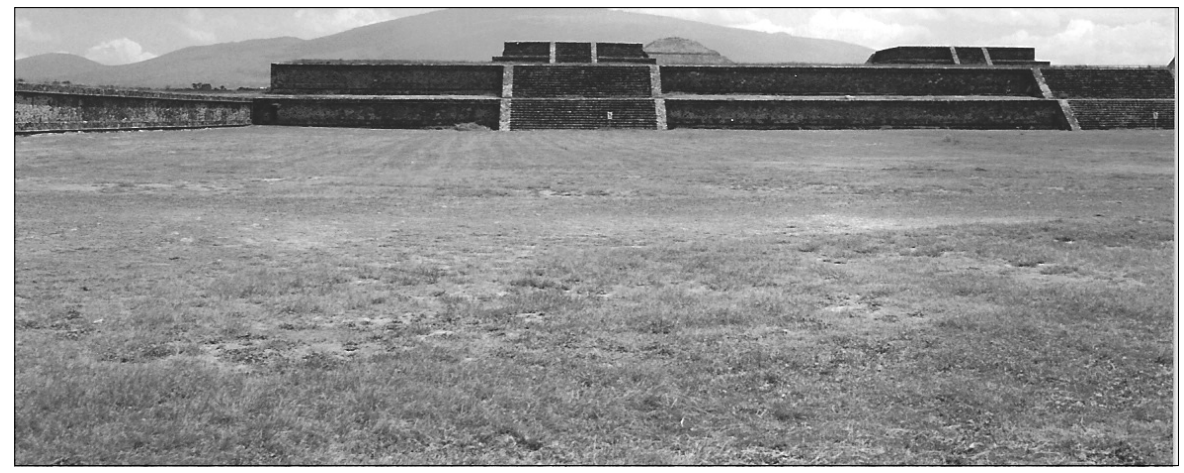

Fото 1: El punto de vista nahua identifica la totalidad de lo prehispánico con las culturas del Centro de México. En la imagen, vista parcial de Teotihuacán.

$\mathrm{Al}$ adentrarse uno en las salas en que aparecen referencias a los chichimecas en el Museo Nacional de Antropología (MNA), llama la atención, en primer lugar, la desconexión histórica que se establece entre el pasado de dichas culturas y las de los actuales habitantes en los mismos territorios. No es, con todo, una constante del MNA, pues este confinamiento de los chichimecas al tiempo arqueológico desconectado del presente no ocurre en otros espacios. Más allá de la glorificación de un determinado pasado, como señalaba Paz, en el que el mal llamado "Calendario azteca" o "Piedra del sol" parece ser el compendio del pasado, presente y futuro de la mexicanidad, la disposición de las culturas del pasado y del presente en dos plantas superpuestas establece una continuidad interrumpida — por la Conquista - entre dos temporalidades: la prehispánica — de la que se quiere 
dar testimonio- y la indígena actual —a quien se homenajea- ${ }^{4}$. Sin embargo, a pesar de esa interrupción, existen continuos puntos de interconexión entre pasado y presente. Así, por ejemplo, cuando se transita por las salas dedicadas a la etnología del sureste mexicano, contemplando lo que allí se ofrece acerca de los pueblos de esa región, es posible asomarse a balcones desde los que se observan, justamente debajo, las salas dedicadas a los mayas. De la misma forma, esos balcones y ventanas de la planta superior del edificio permiten a los paseantes del área arqueológica maya escuchar las músicas actuales del sureste mexicano dotando a aquellos pueblos de una cierta prolongación temporal y estableciendo, en definitiva, un bidireccional encadenamiento histórico entre ambos espacios. Lo mismo ocurre en las salas en las que las escaleras permiten el paso del presente al pasado o viceversa. Más nítida aún es la conexión establecida entre temporalidades para quien pasea parsimoniosamente por los pasillos que unen las diferentes salas etnográficas: desde los ventanales y celosías la vista siempre tendrá presente el patio central (Foto 2) en el que, además del magnífico "paraguas", se distingue el imponente acceso a la sala mexica presidido por las palabras "TOTENYO, TOTAUHCA MEXICA. Nuestra gloria, nuestra fama Mexica."

Nada de eso está presente en las "Culturas del norte". De tal forma que quien transita por ellas tiene la sensación de entrar en un mundo cerrado que no se conecta con ningún otro espacio o tiempo. Como si los chichimecas fueran uno de esos grupos que - según se indica en uno de los carteles de las salas de etnología dedicadas al "Noroeste", en el piso superior- "se extinguieron o se asimilaron rápidamente a la cultura dominante", aunque nada se informe a propósito del cuándo ni del dónde. Tal que no hubiera conexión posible entre los actuales Pueblos de la Sierra - Rarámuri (tarahumaras), Macarawe y Warihió (guarijíos), O'dami (tepehuanes del norte), O'ob (pimas) — y los diversos O'otham (pápagos), entre los que se hallan los Hia'ched o'otham o "Gente de la arena", los Akimel o'otham o "Gente del río" — también llamados "pimas gileños" — y los Tohono o o'tham o "Gente del desierto". Ni conexión tampoco con otros pueblos indígenas del área, como los Conca'ac (seris), Akwa'ala (pai-pai), Ko’lew (liliwa), Cochimí, K’umiai, Cucapá, Yoremes (yaquis y mayos) y Metwséneme

\footnotetext{
${ }^{4}$ En la placa que recuerda la inauguración del Museo el 17 de septiembre de 1964 por el presidente Adolfo López Mateos, se señala que "El pueblo mexicano levanta este monumento en honor de las admirables culturas que florecieron durante la era Precolombina en regiones que son, ahora, territorio de la República. Frente a los testimonios de aquellas culturas el México de hoy rinde homenaje al México indígena en cuyo ejemplo reconoce características de su originalidad nacional".
} 


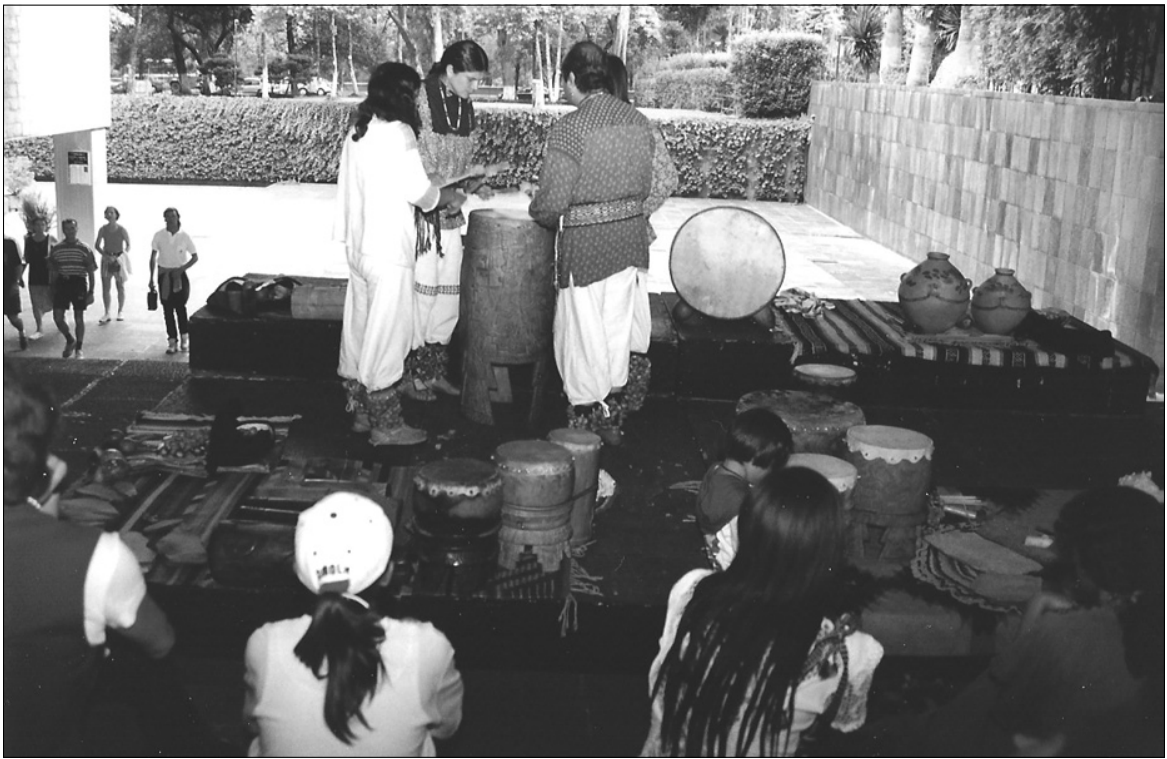

FOTO 2: Turistas contemplando una "recreación" de música y danzas indígenas junto a la cafetería del Museo Nacional de Antropología de México.

(kikapúes), los cuales siguen, según se indica en la mencionada sala, viviendo en los mismos territorios. O que viven en territorios aledaños, si no los mismos, aunque en lugar de ser considerados del "Noroeste" lo sean del "Gran Nayar", como acontece con los Wixaritari (huicholes), Coras o Tepehuanes. Pensar, por supuesto, en algún tipo de relación con los miles de mestizos que viven en los mismos lugares se antoja, desde esta perspectiva, delirio.

Y todo ello a pesar de que se reconoce implícitamente una posible simultaneidad temporal y espacial cuando se asevera que la oscilación "microbanda-macrobanda", como patrón de asentamiento de la época prehispánica, no pudo detener la Conquista, como consecuencia de los "constantes conflictos intertribales" originados por los pactos que los conquistadores habrían realizado con los grupos más pacíficos para someter a otros "más aguerridos como los seris, apaches y yaquis".

Aun así, la desconexión entre la sala de arqueología dedicada al "Norte" y la de etnología dedicada al "Noroeste", la una sin prolongación temporal posible, la otra sin antecedentes históricos más allá de ciertas pinceladas precolombinas y de una enumeración de las rebeliones yaquis no totalmente contextualizadas, plantea, al establecer temporalidades disímiles, espacialidades inconexas. 
Las sorpresas no son menores cuando se atiende al contenido de lo expuesto en la sala "arqueológica", que se inicia con una clara contraposición entre, literalmente, "bárbaros" y "agricultores": "en esta Gran Chichimeca no sólo convivieron teochichimecas (bárbaros), sino también agricultores sedentarios" (González Licón 2005: 2). Más allá de la posible confusión entre teochichimecas y chichimecas, el recorrido por las maquetas y restos arqueológicos conlleva una reiterada identificación entre civilización y agricultura, con el subsiguiente menosprecio de la vida nómada. De hecho, la historia de la región se presenta como un continuum de desarrollos agrícolas que, por motivos ecológicos o climáticos, son sustituidos en épocas de crisis por vidas seminómadas que convierten al lugar en mero espacio de tránsito. Así ocurre cuando, tras alabar la cultura Chupícuaro, una "sociedad agrícola compleja" del siglo V a. C., en la que se producían intercambios a larga distancia de todo tipo de objetos, se señala que una vez que ésta entró declive, "entre los años 700 y 900 d. C. la zona centro de Mesoamérica septentrional es el lugar de tránsito de poblaciones que migran del sur al norte, como en sentido inverso" (ibid:: 6). A pesar de estos declives, el carácter mismo de "corredor" ofrecía las posibilidades de recuperación del área, pues "durante el siglo sexto o principios del séptimo, grupos mesoamericanos se expandieron hacia el norte en lo que hoy es Zacatecas y Durango (Fase Ayala-Las Joyas)" (ibid:: 9), dando origen a lugares como Altavista y La Quemada que, en el caso de esta última fortaleza, lograron una integración regional elevada, merced al control de una gran red de caminos.

Conviene destacar, por tanto, que la imagen que ofrece el Museo Nacional de Antropología mexicano del actual territorio de la Gran Chichimeca sitúa el florecimiento de esta región, a pesar de sus épocas críticas, entre el momento en que los agricultores del centro del país se la arrebataron a los nómadas hace 2.500 años y la fecha en la que éstos, tras 1.500 años, la recuperaron de nuevo:

Hacia el siglo V a. C. se inicia un movimiento de expansión de la frontera septentrional de Mesoamérica. El poblamiento y la colonización de una gran franja del territorio del centro norte del país se debieron al avance de agricultores organizados; quienes, en forma pacífica o enfrentados a la población nómada, cazadora-recolectora, lograron adueñarse y asentarse en aquellas tierras. Las primeras aldeas agrícolas en la frontera norte surgen así como el resultado de un proceso de adaptación y aprovechamiento de los recursos regionales, donde las culturas Chupícuaro del Altiplano Central y de la región de la Costa de Veracruz, van a incidir en los desarrollos locales. Durante el periodo Clásico (150-900 d. C.), la frontera norte alcanza su máxima extensión, que incluye la Sierra de Tamaulipas, la Cuenca del Río Verde y el Tunal Grande en San Luis Potosí; Querétaro, Guanajuato, Aguascalientes, Zacatecas y Durango. Ahí tienen lugar 
complejos desarrollos regionales que mantienen una amplia red de contactos con sus vecinos de la Mesoamérica nuclear, así como con los pueblos agrícolas, hohokam en el noroeste, y los hopewell en el noreste, en el actual territorio de los Estados Unidos [...]. Después de quince siglos de florecimiento, la Mesoamérica septentrional se colapsa [...], la frontera norte se desploma y pueblos cazadoresrecolectores nómadas conocidos como "chichimecas", toman a su cargo la región hasta la conquista hispana (ibid.: 11).

Si bien no es baladí que en la sala referida se traten como parte de las culturas "nacionales" las de los Hohokam, Mogollón, Anasazi o las del río Mimbres, que se desarrollaron en territorios que en algún momento fueron mexicanos y hoy se encuentran en Arizona, Nuevo México, Utah o Colorado 5 , para el objeto de nuestra reflexión resulta más relevante esa irrupción de unos chichimecas — sin que se sepa de dónde salieron ni dónde habían estado hasta entonces- que se hicieron cargo de la región hasta la conquista española. Como si la llegada de los nómadas iniciara una decadencia cuyo ocaso máximo se continuara con la conquista y, al mismo tiempo, una cierta interrupción en la región de la mexicanidad: ésta se habría iniciado en épocas remotas y conducido a las culturas agrícolas de Chupícuaro, interrumpiéndose al final del postclásico temprano (900-1.200 d. C.) para ser recuperadas tras la Independencia en un presente que aún continúa. Esa interrupción temporal tiene su correlato espacial de forma tal que la exposición museística parece asumir la existencia de dos áreas —el Suroeste norteamericano y Mesoamérica - y entre ambas una gran nada:

a partir del 700 d. C. la presencia de algunos ríos en esta región ["el Suroeste americano"] hizo posible el desarrollo de sociedades agrícolas sedentarias entre las que destacan los hohokam, mogollón y anasazi, quienes domesticaron al guajolote, cultivaron el maíz, frijol, calabaza, tomate y chile. Para incrementar su producción agrícola, y evitar la erosión, prepararon terrazas y construyeron canales que conducían el agua a mayores distancias. Su forma de organización social no

${ }^{5}$ Recuérdese que en la mencionada placa inaugural del Museo se indica expresamente que "El pueblo mexicano levanta este monumento en honor de las admirables culturas que florecieron durante la era Precolombina en regiones que son, ahora, territorio de la República". Habida cuenta de que no ocurre lo propio con las culturas mayas guatemaltecas o de Belice, por ejemplo - a las que apenas se alude, a pesar de la unidad que tuvieron con las que vivieron en el territorio chiapaneco o yucateco-, habría que pensar que la presencia de Hohokam, Mogollón o Anasazi como parte indisociable de la historia de México — aunque mucho antes de la creación del paísconlleva una solapada reivindicación de territorios perdidos con la firma del Tratado de Guadalupe Hidalgo de 1848, por el que México hubo de entregar a los Estados Unidos dos millones de kilómetros cuadrados que incluían la totalidad de los actuales Estados de Arizona, California, Nevada y Utah, así como grandes espacios de Colorado, Nuevo México y, en menor medida, Wyoming. 
llegó a ser tan compleja como la mesoamericana, sin embargo son evidentes las relaciones y contactos entre ambas. En medio de estas dos regiones está la Gran Chichimeca (ibid:: 18).

El vaciamiento de la Gran Chichimeca y la consideración negativa de sus moradores han sido reforzados desde otros ámbitos que exceden a lo mexicano. Tal es el caso de la conocida National Geographic Society, que publicara en 1968 el mapa de "La Tierra de la Serpiente Emplumada"6. En este Mapa Arqueológico de Mesoamérica, sucesivamente reimpreso, el contraste entre los numerosos restos arqueológicos que se sitúan en el centro y sur del país es notable: mientras las dos primeras áreas aparecen llenas de referencias notorias, todo aquello que se sitúa allende el michoacano territorio purépecha aparece en blanco, como un inmenso vacío. Algo semejante acontece con el mapa histórico denominado North America Before Colombus (impreso en diciembre de 1972 en Washington) que incluye una división en 12 áreas del territorio americano desde el Polo Norte hasta la frontera panameño-colombiana ${ }^{7}$ y que muestra un gran vacío entre el centro de México y los espacios al norte de la actual frontera mexicano-estadounidense, sólo salpicado por cuatro nombres aislados: La Quemada, Altavista de Chalchihuites, La Candelaria y Casas Grandes.

$\mathrm{Y}$, sin embargo, lo cierto es que este territorio, mucho antes de que Mendoza y Nuño de Guzmán llegaran con la armada más grande que conociera el Continente para aniquilar o desplazar a sus habitantes, estaba habitado por miles de ellos (sólo los O’odham o pápagos, de la cuenca de Phoenix, eran hacia el año 1.300 de nuestra era entre 30.000 y 60.000 personas) ${ }^{8}$ (Cordell 2001: 169). Como lo siguió estando después, a pesar de la

\footnotetext{
${ }^{6}$ La relevancia de la National Geographic en la conformación de un determinado imaginario de los pueblos y lugares "exóticos" ha sido puesta de manifiesto por Lutz y Collins (1993), quienes, además, señalan que México es uno de los lugares a los que esta sociedad ha prestado más atención: entre 1950 y 1986 fueron publicados 20 artículos sobre este país, los mismos que sobre Brasil, sólo por debajo de los 23 que hubo sobre Japón y los 21 acerca de India (ibid: : 120).

7 Según este mapa, que complementa al repertorio denominado Indians of North America, las áreas culturales en que este inmenso territorio se divide son las siguientes: Artic, Subartic, Northwest Coast, Plateau, Great Basin, California, Southwest (que incluiría la mayor parte del territorio chichimeca), Great Plains, Northeast, Southeast, Middle America y Caribbean Area.

${ }^{8}$ Si bien en el siglo XVII esta población se había reducido — sin que haya acuerdo respecto de las causas- a poco más de tres mil personas, hasta el punto de que "Casas Grandes, la enorme aldea hohokam poseedora de una casa observatorio de cuatro pisos, erigida sobre una elevada plataforma, yacía en ruinas en 1694 cuando el padre Eusebio Kino celebró la primera misa ahí" (Cordell 2001: 167).
} 
guerra. En parte, porque las rutas que establecieron los naturales prehispánicos de la Gran Chichimeca — tanto en su deambular nómada como para el intercambio de todo tipo de objetos, o para desplazarse por motivos religiosos-, fueron aprovechadas posteriormente en la Colonia para desarrollar el comercio (Braniff 2001b), del mismo modo como hoy estas rutas siguen siendo transitadas por las miles de personas que, con variados objetivos, buscan la frontera norteña.

En este sentido, la consideración de la pluralidad y diversidad como elementos indisociables de la mexicanidad que, a la vez que las regiones consolidan su influencia, se va asentando lentamente en el conjunto de la sociedad, está propiciando un notorio cambio en el aprecio hacia los chichimecas. Vista la historia del país a través de la articulación de redes pluri-referenciales, por las que los distintos pueblos que la han conformado se han interrelacionado de formas distintas, la superioridad de alguno de ellos deja de ser evidente y se sustituye por la complementariedad, a la vez que se descubre la perversión resultante de aplicar esquemas políticos contemporáneos al pasado. En este contexto, traer el nombre de la tierra nómada (Fábregas 2003), de la Gran Chichimeca, al primer plano de la reflexión, supone reconocer la existencia de la continuidad de procesos históricos interconectados en un complejo entramado de sociedades y culturas con una relativa especialización productiva vinculada a entornos particulares: no es lo mismo el de Mesa Verde, por ejemplo, que el de Colotlán, Jalisco. Tampoco se pueden obviar las alteraciones ecosistémicas que, contrariamente a lo que defiende una estática y sesgada concepción del desierto, se han producido en los últimos 500 años, con los redimensionamientos que tanto los conquistadores y la colonia, en primer lugar, como más recientemente la Globalización (Maisterrena y Mora 2000), han provocado en las aludidas redes sociales y viarias, generando transformaciones paisajísticas y culturales muy relevantes.

\section{EXTRAÑAS CONEXIONES: DE LOS CHICHIMECAS A "LA GRAN CHICHIMECA"}

La cada vez más notoria atención a la pluralidad, junto al nuevo papel que las regiones están adquiriendo en la construcción nacional mexicana, han propiciado un paulatino aprecio tanto en las calles como en la Academia del imaginario chichimeca. Aunque algunos de estos cambios son todavía muy sutiles, otros se manifiestan de forma explícita. En cualquier caso, unos y otros pueden vislumbrarse atendiendo a hechos y situaciones particulares como las que a continuación señalaré, y que, si bien en apariencia no tienen nada que ver entre sí, revelan, cuando se los interconecta, indicios de esta transformación. 
Empecemos con lo que acontece en el Tianguis Cultural de Guadalajara, Jalisco9. Aprieta el sol a mediodía y los caminantes pasean rebuscando entre los múltiples productos que allí se ofrecen a la venta: libros, discos, artesanías, etc. Entre la música que se escucha por doquier sobresale la potente percusión, permanentemente acompañada de acordeones, de El Gran Silencio, un grupo musical que da a sus oyentes la bienvenida "to the chuntaro's land", a la vez que reivindica un "nuevo Freestyle norteño"10. Las rolas (canciones) del grupo se suceden introducidas por diferentes locutores radiofónicos regiomontanos. Tras escucharse la voz perfectamente modulada de uno — "20 grados centígrados en esta mañana”-, el grupo "chuntero" ataca una nueva canción:

El Gran Silencio está consciente dónde nacen las canciones que se canta en los camiones y se lleva a pasear por todo México lo mágico de los corazones de la gente, de su estado, y he estado diciendo y cantando en el escenario cual canario las aventuras de la raza chichimeca, porque acá todos somos del Norte y gritamos iipura yesca!!

Mas ¿no habían desaparecido los chichimecas? ¿Cuáles son las aventuras de estos nuevos chichimecas que cantan con "el canto de la serpiente" y disfrutan de la "rica sabrosura que se baila y se goza con la raza que le gusta apostarle a la vida que se vive en el norte, en el merito Nuevo León”?

9 A pesar de que el término "tianguis" viene referido a "mercados" informales que se reiteran en fechas señaladas en lugares determinados, semejantes a los que en España se conoce con el nombre de "rastros", en el caso del Tianguis Cultural de Guadalajara se trata de una asociación civil perfectamente articulada, con un presidente y un consejo administrativo que, además de organizar un mercadillo en el que se exponen básicamente "productos culturales locales" y que incluye una zona específica para Organizaciones No Gubernamentales para el Desarrollo (ONG'D), promueve otras actividades en ámbitos y aspectos relacionados con el mundo cultural, como la organización de conciertos, exposiciones, eventos, etc. Hay que señalar que el carácter "alternativo" del Tianguis le genera continuos problemas con las administraciones, particularmente con el Ayuntamiento de Guadalajara, que se sustancian en las reiteradas intimidaciones y provocaciones, en ocasiones con actos violentos, que sufren los expositores del Tianguis.

${ }^{10}$ El movimiento juvenil "chuntaro" nace en Monterrey como una variante del cholismo importado de Los Ángeles, California, "con una fuerte influencia de la cultura del narcotráfico desde Colombia y de la cultura de la migración a los Estados Unidos. Con una actitud más propicia a las mezclas culturales entre lo mexicano y lo gringo, evidenciado principalmente en su forma de vestir con los elementos más tradicionales del cholismo (paliacate, mezclilla, red en la cabeza, wainitos, etc.), junto con alguna playera o jersey de equipos norteamericanos de fútbol americano, béisbol y hockey sobre hielo, esta nueva generación de jóvenes expuestos a la migración internacional encuentra sentido en los referentes culturales provenientes de ambos lados de nuestra frontera norte" (Marcial 2006: 109). 
¿Quién es esa raza chichimeca que, contra sus vecinos del otro lado de la frontera, tal vez también contra los de centro, refuerza su identidad norteña en otra de sus canciones?

I like to live en mi tierra, I like to live in América. Por eso mira cómo peleo por mi family, por eso mira cómo peleo para siempre por estar aquí. En el otro lado soy un Mexican more. I'm very, very hungry de todito tu amor. Look at me!, look at me!, para que veas lo que ves. Si me han de matar mañana, que me maten en inglés y esta vez te lo digo de la cabeza a los pies: this is your end, my only friend...

¿Qué contingencias suceden en el cotidiano vivir de los que "van gritando ipura yesca!, como rama de mezquite o palo seco del ocote", que puedan hacerse coincidir con las de quienes, siguiendo al Arzobispo de Durango, llegaron en peregrinación a la Basílica de Guadalupe en junio de 2005? En aquella mañana, los presentes en la Basílica del Tepeyac, en la Ciudad de México, pudieron escuchar cómo Monseñor Héctor González Martínez, Arzobispo de Durango, iniciaba la homilía de la CXII peregrinación que desde dicha archidiócesis se hacía a la mencionada basílica, con un saludo a María de Guadalupe seguido de las siguientes palabras:

Nosotros somos chichimecas, que venimos de las llanuras esteparias de los Zacatecas y de las zonas montañosas de los tepehuanes con el gusto de saludarte y afianzar nuestra identidad humana, cristiana y sacerdotal. Aquí estamos como te explicó nuestro hermano el chichimeca Juan Diego para "seguir las cosas de Dios que nos dan, que nos enseñan quiénes son las imágenes de Nuestro Señor: nuestros sacerdotes" (González Martínez 2005).

Y si la homilía se iniciaba con un nítido "nosotros somos chichimecas", tras las pertinentes explicaciones teológicas y la vindicación de la labor sacerdotal, inherente al carácter de la peregrinación, se concluía con un conjunto de peticiones — solicitud a la Guadalupana de intercesión por las familias, los maestros, los niños y jóvenes, los servidores públicos, los seminaristas, etc. - cuyas últimas palabras, después de demandar la necesaria lluvia, fueron las siguientes:

Intercede por nuestros campos que se dañan por la sequía y los incendios; intercede por nuestros campesinos para que no abandonen la tierra, que la amen, que se arraiguen y sigan haciendo producir esta gran tierra chichimeca (González Martínez 2005).

Tal pareciera que tanto los jóvenes norteños que escuchan a El Gran Silencio como los campesinos durangueses — chichimecas, según el arzobispo- se consideran, de algún modo, parte de los desheredados, de los que no tienen cabida en las historias oficiales, tal como en su día les ocu- 
rrió a los chichimecas. Tal vez por dicho motivo una parte del movimiento antiglobalización tapatío se instala en el mismo campo cada vez que entrega sus premios Tenamaxtli a los derechos humanos.

El 28 de mayo de 2004 tuvo lugar en Guadalajara, Jalisco, la III Cumbre ALC-UE, de Jefes de Estado y de Gobierno de América Latina, El Caribe y la Unión Europea. Más de doscientas personas de distintas nacionalidades, que se manifestaban contra dicho encuentro convocadas por diversos grupos sociopolíticos agrupados bajo las siglas OMG (Otro Mayo Guadalajara), sufrieron, en diverso grado, la represión policial ${ }^{11}$. Para protestar contra ésta, se creó poco tiempo después la "Coordinadora 28 de Mayo" cuyo objetivo inicial era conseguir la libertad de los numerosos detenidos (más de 120, según la prensa local), petición a la que se sumarían numerosas organizaciones político-sociales, creando en abril de 2005 el Foro Social Guadalajara ${ }^{12}$. Un año después, esta coordinadora se convertiría en el "Centro de Derechos Humanos Coordinadora 28 de Mayo A. C.". Desde entonces, con periodicidad anual, dicha organización hace entrega de sus "Reconocimientos Tenamaxtli" a quienes consideran defensores de la sociedad civil, recordando, según proclamaron en rueda de prensa realizada en la Plaza de Armas de Guadalajara, Jalisco, en diciembre de 2009, al "primer defensor mexicano de los derechos humanos", el jefe Tenamaxtli. A la vez, y desde este mismo año, entregarán los "Contra reconocimientos Tomás de Torquemada" a quienes, a su juicio, se han caracterizado por violar los derechos humanos. De este modo, la recuperación del nombre de Tenamaxtli para unos premios alternativos, así como la autopercepción de los jóvenes norteños — según canta El Gran Silencio- o de los campesinos durangueses — según indica el Arzobispo- como herederos de la "raza chichimeca", incluye una relectura de la Conquista relacionada con una reformulación de la me-

11 El llamamiento a secundar estas movilizaciones contra la cumbre fue apoyado, además, por el Departamento de Estudios Ibéricos y Latinoamericanos del Centro Universitario de Ciencias Sociales y Humanidades de la Universidad de Guadalajara, las Comunidades Religiosas Insertas en Medios Populares (CRIMPO), el Instituto Mexicano para el Desarrollo Comunitario (IMDEC), el Sindicato Nacional Revolucionario de Trabajadores de la Compañía Hullera Euzkadi, el Colectivo Ecologista Jalisco (CEJ), el Movimiento Humanista en Guadalajara y el Centro de Reflexión y Acción Laboral (CEREAL).

12 El 4 de abril de 2005 el comunicado de repulsa por la actuación policial acontecida once meses antes fue firmado conjuntamente por Coordinadora 28 de mayo, Comité Cerezo Guadalajara, Red Insurgente Cultura con Justicia, Coordinadora Intersindical $1^{\circ}$ de mayo, Tianguis Cultural A.C., Amigos de la Barranca A.C., Colectivo de Comunicación Cuatro Vientos, Otro Mayo Guadalajara, Sociedad del Silencio, El Barzón, Red Jalisciense de Derechos Humanos, Promotora por la Unidad en Contra del Neoliberalismo y Convergencia Socialista de Monterrey. 
moria de los vencidos que ensancha notablemente este colectivo con la incorporación de quienes se consideran vencidos por los vencidos ${ }^{13}$.

La consideración de líderes militares como Tenamaxtli (otras veces llamado Tenamaztle) como "primer defensor mexicano de los derechos humanos" o como "defensor de la libertad del hombre americano" — según

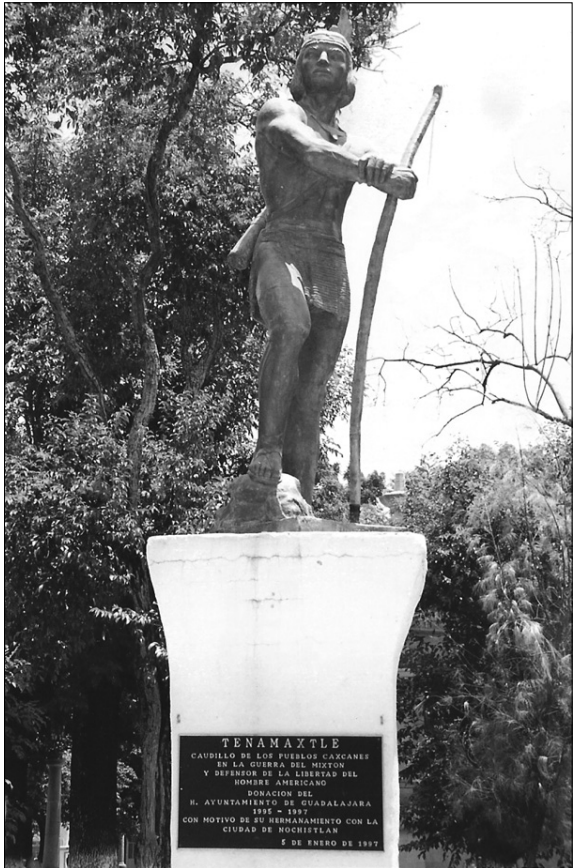

FOTO 3: Escultura de Tenamaxtli en Nochistlán, Zac., en la que se le considera "defensor de la libertad del hombre americano". reza la placa colocada en el pedestal de la imagen escultórica que se le erigió en Nochistlán, Zacatecas, el 5 de enero 1997, con motivo del hermanamiento entre esta ciudad y la de Guadalajara, Jalisco (Foto 3) - corre pareja a la publicación de La flecha en el blanco, la obra en que Miguel León Portilla (1995) reflexiona sobre los diálogos que en su cautiverio vallisoletano tuvieron el líder caxcán y Fr. Bartolomé de las Casas. Según León Portilla (1995: 178), la presencia del líder chichimeco ante el Consejo de Indias, aunque hubiera sido manipulada por Bartolomé de las Casas $^{14}$, otorga a Tenamaxtli "un lugar distinguido en el elenco de quienes han luchado por lo que a muchos parece imposible alcanzar, eso mismo que concisamente expresó otro indio al afirmar que el derecho ajeno es la paz." Al vincular así al jefe chichimeca con Benito Juárez ${ }^{15}$,

13 Y no por ello aliados o sucesores de los vencedores.

14 León Portilla se plantea (1995: 177) la irresoluble cuestión de si la desgracia de Tenamaztle pudo ser aprovechada por el fraile dominico para armarse de razón en los argumentos que tantas veces había expuesto con escaso éxito. Y, aunque concede que Bartolomé de las Casas, por su conocimiento de los vericuetos jurídicos, pudo ser un protagonista que "entre bambalinas" guiara al chichimeca, asevera igualmente que "sería injusto negarle [a Tenamaztle] la capacidad para hacer defensa de sí y de su pueblo. Con las armas, y también razonando, lo había hecho en su tierra".

15 La frase, que algunos atribuyen originalmente, al menos en espíritu, a Kant, "entre los individuos, como entre las Naciones, el respeto al derecho ajeno es la paz", fue pronunciada por Benito Juárez al restaurar la república mexicana en julio de 1867 tras el 
León Portilla lo entronca directamente con la creación de la moderna mexicanidad, estableciendo una continuidad histórica entre el periférico Norte y el Centro (social, político y económico) del país. Por su parte, Alberto Carrillo Cázares (2005: 34), uno de los mejores conocedores de la Guerra Chichimeca, considera que

la denuncia de Tenamaztle contiene ya las premisas de la argumentación jurídica que se comenzará a expresar en las juntas teológicas de 1569-1575 convocadas por el virrey Martín Enríquez de Almanza en busca de justificación ética a la guerra con que pretende someter a esas naciones bravas de los confines septentrionales del imperio español, y donde se escuchará como voz discordante, las de los dominicos que opinan que los primeros agresores son los soldados españoles.

Con ello, se liga a Tenamaxtli con los problemas planteados por los iusnaturalistas de la Escuela de Salamanca, críticos con el rumbo que había tomado la Conquista y, a la vez, se le ubica en la senda precursora de alguno de los preceptos de la vigente Declaración Universal de los Derechos Humanos. No obstante, cuestión diferente —que excede los límites de esta reflexión- es en qué medida la vinculación de los chichimecas con procesos "centrales" de la vida mexicana en un nítido contexto de re-indigenización tras-94 (levantamiento zapatista), que conlleva elevadas dosis de re-mexicanización, no supone igualmente una re-nahualización que, so pretexto de profundizar en la diversidad, la elimina. Paradójicamente, cuanto más se conoce sobre pueblos indígenas particulares, más se desarrolla un discurso globalizado políticamente correcto de defensa de las "culturas indias", lo que supone, de algún modo, una vuelta a la situación colonial —Guillermo Bonfil dixit (1972) — que creó a los "indios". En este sentido, será muy difícil, si no imposible, hablar de grupos post-chichimecas - aunque se hable de postnáhuas- porque, en muy buena media, sólo interesa a ese discurso el indio prehispánico deshistorizado e indefinido.

Sea como fuere, esta nueva mirada de las instancias académicas hacia los chichimecas, coincidente en el tiempo con una multiplicación de páginas web de municipios del norte de México en que se convierte a los actuales vecinos en descendientes de dichos grupos, ha supuesto una mayor visibilidad de los mismos que se traduce en su gradual recuperación (o reinvención, según los casos). Ejemplo de ello serían la denominación del salón de actos de El Colegio de Jalisco, en Zapopan, como "Sala Francisco Tenamaxtli”, o los congresos anuales sobre la Gran Chichimeca que desde 2001 organiza el Instituto de Investigaciones Humanísticas de la Universi-

fusilamiento de Maximiliano I. Hoy día, debido a que se encuentra repetida en multitud de monumentos y edificios por todo México, es conocida por la práctica totalidad de los mexicanos. 
dad Autónoma de San Luis Potosí y que se dedican al análisis de los pueblos indígenas de la región. En todo caso, resulta indudable que parte de esta visibilidad puede relacionarse con la trascendencia de dos hechos académicos de incuestionable importancia fuera del ámbito universitario: la publicación en 2001 del libro que coordinara Beatriz Braniff con el título La Gran Chichimeca. El lugar de las rocas secas y la creación del Seminario de Estudios Permanentes de la Gran Chichimeca (SPECH).

Beatriz Braniff, junto con Richard S. Felger, había sido impulsora de la "Primera Reunión de Antropología e Historia del Noroeste", que tuvo lugar entre el 17 y el 19 de enero de 1974 en Sonora ${ }^{16}$. Las palabras con que se abre el libro que recoge tales trabajos supusieron un auténtico aldabonazo para las ciencias sociales y para el estudio del norte mexicano:

En la antropología, así como en las demás actividades de nuestro país, se ha vivido en una centralización y bajo un dominio casi dictatorial ejercido por el Distrito Federal. Lo primero es el centro, lo demás puede esperar. Y cuando se actúa, a veces con años de atraso, se hace cómodamente en alguna oficina burocrática [...]. Estas resoluciones, en la gran mayoría de los casos, se hacen con increíble ignorancia de la realidad, pues es fuera del DF donde se aplica la medida definida como la mejor por el burócrata capitalino, quien considera en for-

${ }^{16}$ Hay que señalar que, antes de esa fecha, ya existían numerosos estudios acerca del desierto del Norte de México. Sin embargo, la mayoría habían sido realizados por investigadores estadounidenses, como lo probaría la nómina de partícipes en esa reunión que procedían mayoritariamente de instituciones de Arizona: Richard S. Felger, W. Geoffrey Spaulding, Fred Wiseman, Marvin Stakes, Barney Burns, Thomas Naylor, Daphne Overstreet, Dave Stahle, James N. Norris, Lloyd T. Findley, Donald Johnson, Reichard A. Pailes, James S. Griffith, Edward H. Spicer, Thomas B. Hinton, Charles W. Polerz, Julian D. Hayden, Kieran McCarty y Greta Ezell. A éstos se añadieron dos ponentes procedentes de California — Geradl Fish y Thomas G. Bowen-, Herny F. Dobyns, de la Indian Tribal Series, Charles C. Di Peso, de la American Foundation, y Edward Moser, del "problemático" Instituto Lingüístico de Verano. A esta relación solamente se incorporaría, además de la mencionada Beatriz Braniff, otro mexicano: Guillermo Salas, de la Universidad de Sonora. De esta misma universidad también era Ana Elena R. de Aguayo, quien participaría en las discusiones, donde la presencia mexicana ya fue más numerosa - Ignacio del Río, de la UNAM, y Lauro González, Wigberto Jiménez Moreno, Ernesto López, Margarita Nolasco y Cyntia R. de Murrieta, del INAH_- si bien todavía inferior a la de estadounidenses: Roger Dunbier (Universidad de Nebraska), Paul Ezell (Universidad Estatal de San Diego), Frances Gillmor, Emil W. Haury, James E. Officer (Universidad de Arizona), Vance Haynes (Southern Methodist University de Texas), Roger Owen (Queens College, de Nueva York), Carrol L. Riley (Southern Illinois University). Junto a los mencionados, por último, entre los participantes en la discusión, dos procedían de Canadá: N. Ross Crumrine y Kennet G. McIntyre. Además de los ponentes y relatores hubo ciento veinte asistentes registrados, de los que aproximadamente noventa procedían de diferentes instituciones mexicanas y entre los que se encontraban tanto estudiantes como profesionales que comenzaban a destacar, como Guillermo Bonfil Batalla, entre otros. 
ma usual que el medio, la tradición, los problemas y las personas son iguales en todo el país; y que por lo tanto las soluciones también deberán ser iguales (Braniff 1976: 9).

El problema, señalaba la autora, no era sólo de orden político: el centralismo también impregnaba las ciencias sociales, que se empeñaban en aplicar esquemas y categorías que resultaban inútiles para entender la región:

Los esquemas clasificatorios culturales que trabajan con suficiente cohesión en la Mesoamérica prehispánica, colonial y moderna, no se sostienen en el desierto, ni en Sonora; ni siquiera funcionan términos tales como "prehispánico", "colonial", "moderno" y "cultura indígena" con la clara definición con que los empleamos en el México mesoamericano. Tampoco funcionan términos como "prehistoria", "civilización", "arqueología histórica", etc. (ibid: 10).

Veinticinco años después, las "dudas teóricas básicas", a las que aludía Braniff en la apertura de dichos trabajos, empezarían a ser sustituidas por certezas, siquiera provisionales. Justamente por tal motivo, el libro La Gran Chichimeca. El lugar de las rocas secas, del año 2001, clausuraba, por lo menos transitoriamente - como todo en la ciencia social-, algunas incertidumbres. Así, de entre las muchas virtudes que atesora esta obra no es la menor la de enterrar la polémica respecto de la denominación de la región en cuestión, estableciendo la pertinencia del término "Gran Chichimeca". En cualquier caso, el tratamiento integrado de la región por una pléyade de arqueólogas especialistas en la misma - junto a Beatriz Braniff participaban en el proyecto María de la Luz Gutiérrez, Elisa Villalpando, Marie-Areti Hers y Linda S. Cordell— ofrecía una visión sistemática del conjunto del territorio que posibilitaba una vindicación de lo diferente pero igual en valor. Esta restitución era totalmente necesaria por cuanto gran parte de los numerosos estudiosos que a lo largo de los años habían analizado aspectos fragmentarios de la Gran Chichimeca - particularmente notorio en el caso de la arqueología - se habían visto en la necesidad de remarcar lo igual-estructural de todo el pasado mexicano para mostrar que, en última instancia, todo desarrollo venía del centro del país. En este sentido, el libro coordinado por Braniff, al mostrar las múltiples interrelaciones que históricamente se habían sucedido tanto en el interior de la región como con los pueblos que la circundaban por el norte y el sur, facilitaba la apertura a otras perspectivas y evitaba una imagen subordinada de los grupos chichimecas; como ya sugiriera Brigitte Boehm de Lameiras en 1986 respecto de los mesoamericanos sin tener que acudir a una concepción estructuralista. Marie-Areti Hers (2001: 262), una de las arqueólogas que mejor conoce la región, reclamaba esta apertura enriquecedora al reconocer que algunos modelos arqueológi- 
cos que se habían intentado aplicar al Norte mexicano resultaban poco operativos:

Los modelos que los arqueólogos hemos intentado usar para entender tan compleja polifonía de múltiples culturas, paisajes contrastados y espacios ilimitados, se vuelven torpes. Inspirados en mundos muy diferentes, de ciudades y estados de comunidades altamente jerarquizadas y tierras densamente pobladas, estos modelos requieren enriquecerse y mudarse a la escucha de nuevas voces. La de los sabios que a través de los siglos han meditado sobre las tradiciones de sus antepasados y han sido escuchados por los suyos para guiarlos en el presente ${ }^{17}$.

A esta apertura contribuiría el Seminario Permanente de Estudios de la Gran Chichimeca (SPECH), al posibilitar el diálogo entre científicos sociales que, desde diferentes perspectivas y disciplinas académicas, trabajan en la misma región. Esta transversalidad terminaría por generar una gran feracidad teórica, que ha trascendido la inicial aceptación de algunos de los postulados y axiomas de la ecología cultural de raíz evolucionista multilineal (la cual, siguiendo a Ángel Palerm, asumían algunos de sus impulsores, particularmente Andrés Fábregas y quien esto escribe). Pero, más allá de otros resultados a que pueda llegar en el futuro, dicho Seminario ha conseguido ya algo que hace pocos años resultaba quimérico: aunar a un número creciente de instituciones académicas en torno al análisis del territorio de los chichimecas y el estudio de las gentes que lo habitan y transitan, dando con ello respuesta, aunque tardía, a lo que ya planteara Braniff en la aludida reunión de 1974: para conocer esta región "la arqueología, la historia, la etnología y la geografía son disciplinas que se necesitan entre sî" (Braniff 1976: 12).

\section{CONOCIENDO EL NORTE DE JALISCO: ANTECEDENTES DEL SPECH}

En julio de 1997, mientras realizábamos trabajo de campo en Los Altos de Jalisco (Tomé y Fábregas 2000, 2002; Tomé 2008), en una reunión celebrada en Teocaltiche - y en la que participamos Gustavo Díaz del Castillo,

${ }^{17}$ La demanda de Marie-Areti Hers incluía una apelación esperanzadora al nuevo indigenismo al considerar que "la voz de los pueblos indígenas", hacedores de historia, permitirá vencer el secular olvido al que han sido sometidos: "es de esperar que, un día cercano, hombres y mujeres indígenas reanuden un diálogo interrumpido hace siglos. Venciendo distancias y diferencias, se sentarán juntos, recibirán de los arqueólogos testimonios dispares de tiempos remotos y volverán a entrelazar sus pensamientos para dar nuevas luces sobre su propio pasado. Se establecerá un diálogo entre pimas y tepehuanes, quienes reconocen en sus palabras un común origen a pesar de las migraciones que los separaron y les depararon destinos tan distintos. Al pie de una roca recubierta de grabados, hopis y huicholes se sentarán bajo la figura de Kokopelli y quizás se vencerá el silencio de tantos siglos de olvido" (2001: 262). 
Tomás Martínez Saldaña, Cándido González, Eliseo López Cortés, Andrés Fábregas y yo mismo- Fábregas planteó la posibilidad de establecer una comparación controlada entre los modos de vida de los rancheros alteños con aquellos que llevaban los del sur de Zacatecas y los del Norte de Jalisco. A fin de cuentas, resulta fácil trazar una línea recta entre Villa Hidalgo y San Martín de Bolaños — ambas localidades en regiones diferentes de Jalisco- que pasa por las zacatenas Jalpa y Tepechitlán (véase Mapa 3). Con tal fin, Fábregas redactó un anteproyecto de investigación sobre el Norte de Jalisco que pudiera servir de base a dicha pretensión, la cual, no obstante, careció, como el segundo proyecto redactado, de apoyo por parte de las administraciones a las que fue presentado. En este contexto, con el fin de hallar suficientes argumentos teóricos, pero con fundamento empírico, con los que mostrar que la región era digna de ser estudiada — pues tal pareciera que ése era el obstáculo mayor ${ }^{18}$ - , decidimos emprender un viaje de campo exploratorio a la misma en el que, amparados en la apoyatura que para tal menester nos proporcionaría El Colegio de Jalisco, participamos un heterogéneo grupo compuesto por Andrés Fábregas, el etnomusicólogo Arturo Chamorro, el economista Larrauri, el fotógrafo Alberto G. Barbosa y quien esto escribe.

El viaje resultó ser más lento de lo programado. Nuestra primera intención era empaparnos de las variedades del paisaje, de sus poblados y la forma de asentamiento, de la existencia de posibles cortinas ganaderas y potreros, de la vegetación arbustiva y agrícola y de todo aquello que, en definitiva, en un primer acercamiento nos permitiera sentar bases para una posterior reflexión. Tras detenernos en Monte Escobedo, en el Estado de Zacatecas, tomamos Mezquitic, nuevamente en Jalisco, como base para nuestra exploración. En dicho municipio tuvimos una larga entrevista con el delegado del Instituto Nacional Indigenista en la localidad. Con la presencia de Nacho Bonilla, quien había sido alcalde del lugar, la entrevista se centró fundamentalmente en la problemática derivada de la invasión de tierras huicholas por colonos nayaritas, las repercusiones y respuestas que este suceso estaba generando, y en otros problemas, tales como la extensión del S.I.D.A., el papel de las ONG'D, la emigración, etc.

${ }^{18}$ Se puede decir que la región Norte del Estado de Jalisco es desconocida por la mayoría de los jaliscienses, que tiene una difusa percepción de un espacio asociado a "los huicholes". A este desconocimiento han contribuido numerosos factores, que van desde la ausencia de mapas adecuados (Tomé 2001) al abandono por parte de las administraciones. Hasta 1986 no se hizo la carretera que une la región con la capital del Estado, Guadalajara. Hasta esa fecha, llegar desde Guadalajara a Colotlán suponía alrededor de catorce horas, y desde este lugar hasta Mezquitic, aproximadamente un día completo de carretera. 


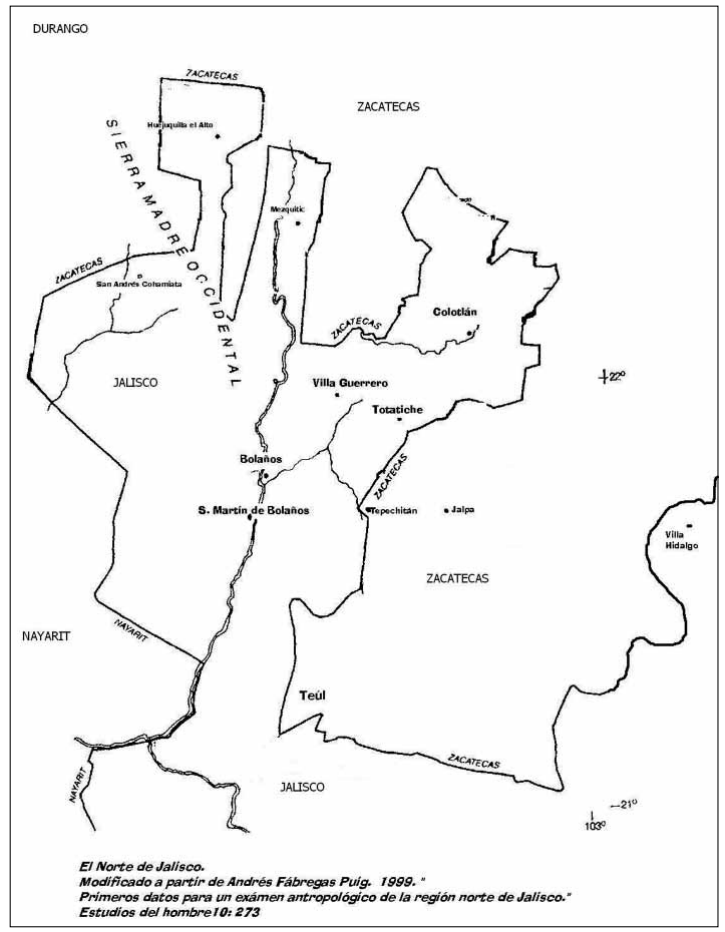

MAPA 3: El norte de Jalisco.

Estando en Mezquitic, acudimos a menudo a la tienda de abarrotes, mejor nutrida que cualquier macroplaza tapatía. En ella se puede adquirir cualquier cosa imaginable, desde gasolina a chaquira ${ }^{19}$. Pero, con todo y arpa, no era nuestro objeto comprar nada, sino ver y, sobre todo, ser vistos, pues cualquier persona que llega a Mezquitic, sea cual sea su objeto y procedencia, pasa por la tienda, que se convierte así, tanto en un instrumento de control social como en irradiador de noticias. La tienda es, en efecto, un importante centro de carácter regional que hace que, para ciertos ámbitos, los lugareños la consideren de mayor relevancia que la propia Presidencia Municipal. Cierto que en ella no se toman decisiones, pero es el aglutinador más importante de noticias de todo el lugar.

De interés fue también desayunar donde "la mentada Jovita", el patio particular de una casa privada, en la que compartíamos - en mesas separadas- huevos con una familia wixarika (huichola) y el cuerpo local de la policía de Mezquitic, que, en riguroso orden y de uno en uno, pasaba a ducharse cada mañana.

19 Baste decir, a título de ejemplo, que en ella compró Arturo Chamorro un arpa. 
De la visita a la hacienda de San Antonio de Padua nos impresionó tanto la magnificencia del entorno como los silos cónicos, cual viviendas capadocias, que daban una idea de su poderío económico; el mismo que atrajo a las tropas de Villa, cuyo recuerdo se encuentra por doquier en paredes y tejado, más allá de la ruina general del edificio.

Si Mezquitic se antojaba tranquilo, Huejuquilla el Alto sobresaltaba por el movimiento económico y humano que sus calles destilaban: tal parecía que un hormiguero en plena actividad hubiese sido desplazado sobre el suelo. Acogidos por las autoridades del lugar, en parte impresionados porque alguien, fuera de época electoral, se interesara por el Norte de Jalisco, nos ofrecieron todo tipo de colaboración, como ya estaban haciendo con una colega que se encontraba por aquellos lares investigando procesos migratorios mientras, por activa y por pasiva, su clara identidad jalisciense era contrapuesta a su dependencia económica de Zacatecas.

La antítesis de la hacienda de San Antonio de Padua era la de San Juan Capistrano, a la que llegamos a través de un paisaje abrumadoramente bello que, de cuando en vez, exigía el esfuerzo adicional de superar el asombro para recordar que, en medio de tanta grandiosidad, hay actores humanos que lo tienen por escenario cotidiano de sus vidas y en él se mueven modificándolo y acomodándolo. Vacunados contra el riesgo de romántica raíz que lleva a considerar a las personas como meras figuras que pueden ubicarse aleatoriamente en pintorescos cuadros, pudimos conversar con los ancianos habitantes de la solitaria hacienda, todo ruina y degradación, convencidos como estaban de que su muerte equivaldría al adiós de toda la memoria que atesoraban las decrépitas paredes que los albergaban. El recorrido por la Sierra Madre nos condujo, primeramente, hasta un aserradero huichol, donde las explicaciones recibidas nos permitieron tener una visión global de la producción maderera y de su escaso futuro. Por último, antes de abandonar la región, en el fondo del cañón, recorrimos detenidamente Bolaños, con sus imponentes edificios castellanos que elevan sus muros entre el río y la montaña.

Tras dicho viaje, y no pocas trabas, siempre amables y burocráticas, se constituyó un grupo de investigación inicialmente compuesto por Andrés Fábregas, Arturo Chamorro, Louis Cardaillac, Pedro Tomé, M. Ángeles Valencia, Arturo Camacho, Angélica Peregrina, Rosario Realpozo, Estrellita García y Mario A. Nájera, cuyo objetivo fundamental, con el apoyo de El Colegio de Jalisco, era crear conocimiento sobre el Norte de Jalisco. El incremento de apoyos institucionales procedentes de la Subsecretaría de Investigación Científica de la Secretaría de Educación Pública y, posteriormente, de la Secretaría de Medio Ambiente del Gobierno de Jalisco y, sobre todo, gracias al impulso definitivo que supuso la apertura, bajo la dirección de 
Cándido González, del Centro Norte de la Universidad de Guadalajara en Colotlán en el año 2001, permitió constituir un equipo de trabajo multidisciplinar formado por antropólogos, economistas, historiadores y biólogos que iniciara los trabajos de campo.

$\mathrm{Si}$, primariamente, el equipo en cuestión se planteó la comparación de los estilos de vida de los rancheros del Norte de Jalisco, el Sur de Zacatecas y Los Altos de Jalisco, los datos preliminares fueron confirmando la necesidad de ensanchar ese espacio para incluir también a habitantes de Aguascalientes y Durango. Esta misma impresión fue confirmada por los asistentes al "Coloquio El Norte de Jalisco. En Homenaje a Manuel Caldera", que tuvo lugar en Colotlán en noviembre de 2000 (Fábregas 2001) y ampliada por los que un año después (noviembre de 2001) se reunieron en la misma ciudad para desarrollar el Segundo Coloquio del Norte de Jalisco (Fábregas 2002) y en el que se planteó abiertamente la necesidad de abarcar todo el territorio cubierto por los antiguos chichimecas.

\section{"El SEMINARIO PERMANENTE DE LA GRAN CHICHIMECA"}

Con las bases teóricas emanadas de los dos coloquios mencionados, más el aporte de nuevos investigadores de instituciones diversas, Roberto Castelán, en nombre del Campus de los Lagos de la Universidad de Guadalajara, Andrés Fábregas por El Colegio de Jalisco y Tomás Calvillo como presidente de El Colegio de San Luis, firmaron en la Sala Miguel Caldera de esta última institución —nombre que rememora al capitán que concluyó formalmente la Guerra Chichimeca (Powell 1997) — un convenio para crear lo que, inicialmente, denominarían "Seminario Permanente de Estudios del Centro, Norte y Occidente de México". En esa dirección, el primer paso que se dio fue la convocatoria de una reunión científica que tuvo lugar en la misma sala de San Luis Potosí el 29 de octubre de 2002. Allí, en una evaluadora reunión final tras las intensas discusiones, se consideró oportuno definir la región por sus características propias y no por su posición geográfica en relación con la ciudad de México. Fue así como nació "el Seminario Permanente de Estudios de la Gran Chichimeca" (SPECH), cuya primera convocatoria formal tendría lugar en septiembre de 2003 en la sede del Centro Universitario del Norte que la Universidad de Guadalajara tiene en Colotlán, Jalisco.

Siguiendo el esquema de los mencionados coloquios sobre el Norte de Jalisco, la reunión se abrió con una conferencia magistral, a cargo de Alberto Carrillo Cázares, y fue seguida de cinco mesas de trabajo: antropología, arqueología, ecología cultural, etnología e historia. Todo ello para con- 
figurar dieciocho ponencias, que incluían desde avances preliminares de trabajos varios sobre la Gran Chichimeca a estudios o análisis ya consolidados de temas muy diferentes: desde las estrategias de supervivencia de los campesinos del altiplano potosino al control social de las mujeres de los migrantes, pasando por la apertura de museos, las peregrinaciones a través del desierto, la administración de la minería en la Nueva Galicia, o el papel de la Iglesia Católica en el pasado y el presente regional. Pero, más allá de las aportaciones concretas, la relevancia de esta reunión radicaba en el establecimiento de una colaboración interinstitucional en la indagación de un tema hasta entonces relativamente estigmatizado - los chichimecas - en la que participaban la Universidad de Guadalajara a través de tres de sus campus (CUCSH, CUAAD y CUALTOS), la Universidad Autónoma de Zacatecas, la Universidad Autónoma de Aguascalientes, El Colegio de San Luis, El Colegio de Michoacán y El Colegio de Jalisco (Fábregas, Nájera y González 2005). A mayores, como señalara Fábregas (2005: 10)

Aunque hubo encuentros y desencuentros, prevaleció la voluntad de crear conocimiento acerca de un conglomerado de pueblos que habitaron los espacios identificados bajo el término Gran Chichimeca, y las transformaciones profundas introducidas durante el régimen colonial. Resalta la importancia de discutir el papel de esta macro región en la formación de la nación.

La consolidación del SPECH fue propiciada con la celebración de un Segundo Encuentro un año después en la ciudad de Aguascalientes, dedicado a estudiar la diversidad cultural y la sobrevivencia de la Gran Chichimeca. Si el número de instituciones participantes creció entonces - pues a las presentes en la primera reunión se añadieron la Universidad Autónoma de Coahuila y la Intercultural de Chiapas-, también lo hizo el número de ponentes y de mesas, centradas en tradición oral, historia, patrimonio cultural, arqueología, antropología, ecología cultural y etnomusicología, que iniciaron sus trabajos tras la conferencia magistral de Briggite Boehm Schoendube sobre las políticas del agua en las relaciones entre el desierto y el centro del país ${ }^{20}$.

La celebración en Zacatecas de la tercera reunión vendría a suponer la definitiva institucionalización del Seminario. Centrado en el análisis regional (Fábregas, Nájera y Román 2008), esta reunión se abriría con la conferencia magistral de Claudi Esteva Fabregat y se articularía en diversas me-

${ }^{20}$ En puridad hay que señalar que, de los campus de la Universidad de Guadalajara que participaron en la primera reunión, en la edición de los trabajos de la segunda (Fábregas, Nájera y Ortiz 2007) no participó el de Los Altos de Jalisco (CUALTOS). A cambio, se incorporó el de Ocotlán (CUCIÉNEGA). 
sas reunidas para discutir sobre frontera, historia, región y cultura, lingüística y toponimia, arqueología y antropología. Igualmente, se iniciarían los análisis sobre las continuidades y discontinuidades en la Gran Chichimeca que un año después se acometerían en Zapopan, Jalisco (Fábregas, Nájera y Esteva 2008), en una reunión, la cuarta, que abriría Juan Luis Sariego.

La movilidad geográfica de este Seminario —que en su V Encuentro llegó a la ciudad de Saltillo para celebrar su reunión en la Universidad Autónoma de Coahuila - le ha permitido también un gran dinamismo en su interior. Con motivo de ese encuentro, modificó nuevamente su ordenación: tras la conferencia magistral a cargo del profesor de la Universidad Wayne State de Michigan José Cuello, las mesas abandonaron la estructura disciplinaria para pasar a ser más temáticas. Se concentraron así los trabajos en una dedicada a los "Orígenes y permanencia de la Gran Chichimeca", otra a la "Configuración de la Gran Chichimeca" y una tercera a "La dinámica sociocultural actual en el ámbito de la Gran Chichimeca”. Además, hubo discusiones genéricas relativas a los once "avances de investigación" presentados, así como un panel de reflexión sobre el propio Seminario y sus direcciones posibles, que coordinaron M. Alberto Nájera — quien desde el primer encuentro desarrolla las funciones de secretario-, Andrés Fábregas, Javier Maisterrena y Alberto Carrillo. Cabe señalar que, más allá de sus publicaciones, de su presencia en prensa y medios de comunicación - que han permitido ponderar "lo chichimeca" a muchas personas allende la academia-, la reunión del SPECH tuvo efectos directos en la Universidad Autónoma de Coahuila: tras el éxito del encuentro celebrado entre el 23 y el 25 de septiembre de 2007, dicha universidad decidió poner en marcha en el siguiente curso académico la licenciatura en historia de la que hasta entonces carecía.

La capacidad autocrítica del Seminario, desarrollada ya en el mencionado panel del V Encuentro, se acrecentó en el siguiente, celebrado en noviembre de 2008 en Ocotlán, Jalisco. En esta sexta reunión, tras la conferencia magistral de Luis Aboites, la primera mesa se dedicó por completo al análisis de las cuatro memorias ya publicadas. A mayores, se realizaron cuatro mesas sobre el estado de la cuestión en los estudios históricos, arqueológicos, antropológicos y de fuentes de la Gran Chichimeca. Éstas se complementaron con otras tres, dedicadas a avances de investigación en las que se discutieron catorce trabajos.

Por último, el VII Encuentro del SPECH, celebrado en San Luis Potosí en octubre de 2009, ha permitido aunar definitivamente la imagen del antaño denostado flechero con las de las instituciones académicas (Foto 4).

Posiblemente no fuera casualidad que en este último encuentro las sesiones se abrieran con una conferencia magistral desarrollada por alguien ajeno al ámbito del conocimiento teórico: Pedro Pantoja, director de la Casa 


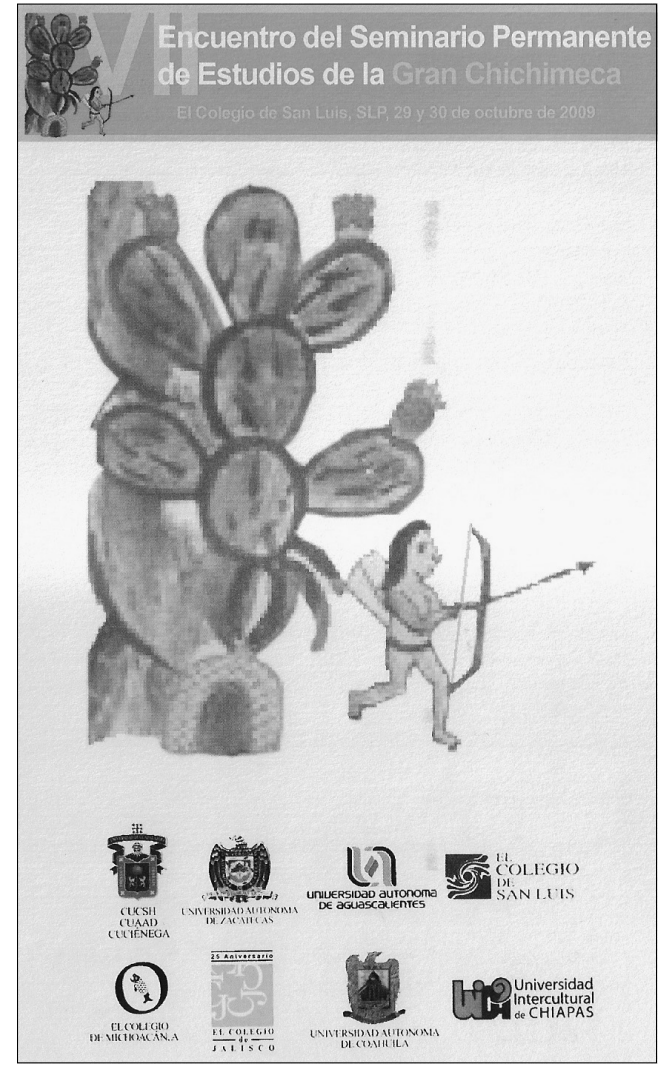

Fото 4: El antaño denostado "flechero" chichimeca aparece ahora junto a los emblemas institucionales de ocho instituciones académicas. del Migrante de Saltillo. Pantoja puso nítidamente de manifiesto cómo son tratados quienes nomadean a través del territorio chichimeca en busca de la frontera norte; la misma que franqueará el SPECH cuando celebre en California su siguiente Encuentro, que ya será el VIII.

Mientras tanto, la proyección social que estas reuniones, así como sus publicaciones, está teniendo —más allá de sus iniciales objetivos teóricos-, parece contribuir de manera decisiva a conformar una imagen distinta de la que hasta ahora había dominado tanto sobre los chichimecas como sobre su territorio; al menos, en las áreas que ellos habitaron. Cosa distinta es, naturalmente, lo que ocurra en otros lugares más o menos alejados de este espacio.

\section{BIBLIOGRAFÍA CITADA}

Bandelier, A. 1880. "On the Social Organization and Mode of Government of the Ancient Mexicans", en Twelfth Annual Report of the Trustees of the Peabody Museum of American Archaeology and Ethnology II (3): 557-699. Cambridge, Ms.. EE. UU.: Salem Press.

Boehm de Lameiras, B. 1986. La formación del Estado en el México prehispánico. Zamora, Mich.: El Colegio de Michoacán.

Bonfil, G. 1972. "El concepto de indio en América: una categoría de la situación colonial". Anales de Antropología 9:105-124.

Braniff, B. 1976. "Introducción", en B. Braniff y R. S. Felger (coords.), Sonora: Antropología del desierto. Primera Reunión de Antropología e Historia del Noroeste: 9-14. México: INAH.

Braniff, B. 1989. "Oscilación de la frontera norte de Mesoamérica: un nuevo ensayo". Arqueología 2a época 1: 99-114. 
Braniff, B. (coord.). 2001a. La Gran Chichimeca. El lugar de las rocas secas. México: Jaca Book-CONACULTA.

Braniff, B. 2001b. "Las rutas sagradas y de comercio en Mesoamérica y en el Norte", en B. Braniff, La Gran Chichimeca. El lugar de las rocas secas: 239-244. México: Jaca Book-CONACULTA.

Carrillo Cázares, A. 2000. El debate sobre la guerra Chichimeca: 1531-1585. Zamora, Mich.: El Colegio de Michoacán.

Carrillo Cázares, A. 2003. Fray Guillermo de Santa María: Guerra de los chichimecas. México 1575-Zirosto 1580. Zamora, Mich.: El Colegio de Michoacán-Universidad de Guadalajara-El Colegio de San Luis. $2^{\mathrm{a}}$ edición.

Carrillo Cázares, A. 2005. "Don Francisco Tenamaztle, tatoán de la provincia de Noschistlán y Xalisco pide cumplimiento de justicia sobre su levantamiento y defensa natural. Consejo de Indias, Valladolid, España (1555-1556)", en A. Fábregas, M. A. Nájera y C. González (eds.), La Tierra nómada: 13-35. Guadalajara, Jal.: Seminario Permanente de Estudios de la Gran Chichimeca.

Cordell, L. S. 2001. "De las aldeas primitivas a los grandes poblados en el Noroeste", en B. Braniff, La Gran Chichimeca. El lugar de las rocas secas: 155-210. México: Jaca Book-CONACULTA.

Fábregas, A. (coord.). 2001. Memoria del Norte. Coloquio en Homenaje a Manuel Caldera. Guadalajara, Jal.: El Colegio de Jalisco-Campus Universitario del Norte de la UdGSecretaría de Educación Pública.

Fábregas, A. (coord.). 2002. El Norte de Jalisco. Sociedad, cultura e historia en una región mexicana. Guadalajara, Jal.: El Colegio de Jalisco-Campus Universitario del Norte de la UdG-Secretaría de Educación Pública.

Fábregas, A. 2003. Reflexiones desde la tierra nómada. Colotlán, Jal.: Campus Norte UdGEl Colegio de San Luis.

Fábregas, A. 2005. "Presentación", en A. Fábregas, M. A. Nájera y C. González (eds.), La Tierra nómada: 7-10. Guadalajara, Jal.: Seminario Permanente de Estudios de la Gran Chichimeca.

Fábregas, A., M. A. Nájera y C. González (eds.). 2005. La Tierra nómada. Guadalajara, Jal.: Seminario Permanente de Estudios de la Gran Chichimeca.

Fábregas, A., M. A. Nájera y J. A. Ortiz (coords.). 2007. Diversidad cultural y sobrevivencia. La frontera chichimeca, una visión desde el siglo XXI. Guadalajara, Jal.: Seminario Permanente de Estudios de la Gran Chichimeca.

Fábregas, A., M. A. Nájera y J. F. Román (coords.). 2008. Regiones y esencias. Estudios sobre la Gran Chichimeca. Guadalajara, Jal.: Seminario Permanente de Estudios de la Gran Chichimeca.

Fábregas, A. M.A. Nájera y C. Esteva Fabregat (coords.). 2008. Continuidad y fragmentación de la Gran Chichimeca. Guadalajara, Jal.: Seminario Permanente de Estudios de la Gran Chichimeca.

González Licón, E. 2005. Culturas del Norte. Cédulas de Sala. México: Museo Nacional de Antropología-Dpto. de Promoción Cultural-CONACULTA-INAH.

González Martínez, H. 2005. "Homilía en la CXII peregrinación de la Arquidiócesis de Durango a la Basílica de Guadalupe", htpp://virgendeguadalupe.org.mx/homilias/05durango.htm.

Hers, M.-A. 2001. "De un nacimiento mítico a un futuro reencuentro", en B. Braniff (coord.), La Gran Chichimeca. El lugar de las rocas secas: 261-262. México: Jaca BookCONACULTA. 
Kirchoff, P. 1943. "Mesoamérica: sus límites geográficos, composición étnica y caracteres culturales". Acta Americana I: 92-107.

Léon Portilla, M. 1995. La flecha en el blanco. Francisco Tenamaztle y Bartolomé de las Casas en lucha por los derechos de los indigenas, 1541-1556. México: Diana-El Colegio de Jalisco.

Lutz, C. y J. L. Collins. 1993. Reading National Geographic. Chicago-Londres: University of Chicago Press.

Maisterrena, J. e I. Mora. 2000. Oasis y espejismo: proceso e impacto de la agroindustria del jitomate en el Valle de Arista, S.L.P. San Luis Potosí, SLP: Secretaría de Ecología y Gestión Ambiental del Gobierno del Edo. San Luis Potosí- CONACYT.

Marcial, R. 2006. Andamos como andamos porque somos como somos: culturas juveniles en Guadalajara. Zapopan, Jal.: El Colegio de Jalisco.

Morgan, L. H. 1985 [1877]. Ancient Society. Tucson, Ar.: University of Arizona Press.

Paz, O. 1967. Puertas al campo. México: UNAM.

Paz, O. 1970. Postdata. México: Siglo XXI.

Powel, Ph. 1977 [1952]. La guerra chichimeca (1550-1600). México: FCE.

Powell, Ph. 1997 [1977]. Capitán mestizo: Miguel Caldera y la frontera norteña. La pacificación de los chichimecas (1548-1597). México: FCE. 1aㅡ reimpresión.

Tomé, P. 2001. "Donde nada hay: límites, desiertos e indefinición política", en A. Fábregas (coord.), Memoria del Norte. Coloquio en Homenaje a Manuel Caldera: 193-197. Guadalajara, Jal.: El Colegio de Jalisco-Campus Universitario del Norte de la UdGSecretaría de Educación Pública.

Tomé, P. 2008. "Una experiencia comparada de trabajo etnográfico entre España y México, o la Ecología Cultural revisitada". Revista de Dialectología y Tradiciones Populares LXIII (1): 121-146.

Tomé, P. y A. Fábregas. 2000. Entre mundos. Procesos interculturales entre México y España. Guadalajara: El Colegio de Jalisco-IGDA-UdG. $2^{\underline{a}}$ edición.

Tomé, P. y A. Fábregas. 2002. Regiones y Fronteras. Una perspectiva antropológica. Guadalajara, Jal.: El Colegio de Jalisco-Secretaría de Educación Pública de Jalisco.

Weigand, Ph. y A. García. 1996. Tenamaxtli y Guaxicar: las raices profundas de la Rebelión de Nueva Galicia. Zamora, Mich.: El Colegio de Michoacán-SEP Jalisco.

Fecha de recepción: 19 de enero de 2010.

Fecha de aceptación: 17 de febrero de 2010

RDTP, vol. LXV, n. ${ }^{\circ}$ 1, pp. 155-184, enero-junio 2010, ISSN: 0034-7981, eISSN: 1988-8457, doi: 10.3989/rdtp.2010.008 